\title{
PENGARUH KUALITAS KEHIDUPAN KERJA TERHADAP NIATAN BERHENTI KERJA DENGAN MEDIASI KEPUASAN KERJA DAN KINERJA KARYAWAN
}

\author{
Indah Handayani $^{1)}$ dan Edi Purwanto ${ }^{2)}$ \\ 1) Manajemen, Universitas Bunda Mulia \\ ${ }^{2)}$ Magister Manajemen, Universitas Bunda Mulia \\ Disetujui 28 Februari 2018
}

\begin{abstract}
This research aims, while exploring the mediating effect of job satisfaction and job performance, to know and explain how quality of work life influence the turnover intentions at the PT. Bina Karya Prima. Research study samples include 103 of the PT. Bina Karya Prima employees. Data collecting used questionnaires, which were shared directly. Data was analysed using the Structural Equation Model (SEM) with PLS software. Research results show that: (1) job satisfaction has a negative and significant influence on the turnover intentions, (2) job performance has a negative and significant influence on the turnover intentions, (3) job satisfaction has not significant influence on the job performance, (4) quality of work life has not a significant influence on the job satisfaction, and (5) quality of work life has a positive and significant influence on the job performance.
\end{abstract}

Keywords: turnover intentions, quality of work life

\begin{abstract}
ABSTRAK
Penelitian ini dilakukan untuk mengetahui kepuasan kerja dan kinerja karyawan memediasi pengaruh kualitas kehidupan kerja terhadap niat berhenti kerja karyawan pada PT. Bina Karya Prima. Sampel penelitian yang diambil berjumlah 103, yang semuanya adalah karyawan PT. Bina Karya Prima. Data dikumpulkan melalui penyebaran kuesioner yang dibagikan secara langsung kepada para responden. Data yang terkumpul dianalisis menggunakan Structural Equation Model (SEM) dengan perangkat lunak PLS. Hasi penelitian menunjukkan bahwa: (1) kepuasan kerja terbukti berpengaruh negatif dan signifikan terhadap niatan berhenti kerja, (2) kinerja terbukti memiliki pengaruh negatif dan signifikan terhadap niatan berhenti kerja, (3) kepuasan kerja tidak terbukti memiliki pengaruh signifikan terhadap kinerja, (4) kualitas kehidupan kerja tidak terbukti berpengaruh signifikan terhadap kepuasan kerja, dan (5) kualitas kehidupan kerja terbukti memiliki pengaruh positif dan signifikan terhadap kinerja.
\end{abstract}

Kata kunci: niatan berhenti kerja, kualitas kehidupan kerja

\section{PENDAHULUAN}

PT. Bina Karya Prima adalah salah satu perusahaan yang bergerak di bidang industri minyak, sabun dan margarine (oil, soap and fat industries) yang telah berdiri sejak tahun 1981. PT. Bina Karya Prima

*Korespondensi Penulis:

E-mail: epurwanto@bundamulia.ac.id telah dikenal sebagai salah satu perusahaan bisnis minyak kelapa sawit yang terintegrasi di Indonesia yang memproduksi minyak goreng, sabun, dan margarin dengan produk unggulan seperti Tropical, Shinzu'i, Forvita, dll. Sebagai salah satu perusahaan yang memiliki peran dalam pangsa pasar consumer goods di Indonesia, khususnya di bidang industri minyak (oil), PT. Bina Karya Prima memiliki tingkat 
pergantian karyawan (turnover) yang tergolong cukup tinggi. Adapun data pergantian karyawan pada PT. Bina Karya Prima seperti terlihat pada Tabel 1:

\section{Tabel 1. Data Turnover Karyawan}

\begin{tabular}{ccccc}
\hline Periode 2016 & $\begin{array}{c}\text { Jumlah } \\
\text { Karyawan } \\
\text { Awal }\end{array}$ & $\begin{array}{c}\text { Jumlah } \\
\text { Karyawan } \\
\text { Masuk }\end{array}$ & $\begin{array}{c}\text { Jumlah } \\
\text { Karyawan } \\
\text { Keluar }\end{array}$ & $\begin{array}{c}\text { Jumlah } \\
\text { Karyawan } \\
\text { Akhir }\end{array}$ \\
\hline Januari & 97 & 4 & 2 & 99 \\
Februari & 99 & 2 & 0 & 101 \\
Maret & 101 & 5 & 3 & 103 \\
April & 103 & 1 & 0 & 104 \\
Mei & 104 & 0 & 2 & 102 \\
Juni & 102 & 2 & 0 & 104 \\
Juli & 104 & 3 & 0 & 107 \\
Agustus & 107 & 1 & 3 & 105 \\
September & 105 & 0 & 3 & 102 \\
Oktober & 102 & 2 & 1 & 103 \\
November & 103 & 1 & 0 & 104 \\
Desember & 104 & 2 & 1 & 105 \\
\hline Subr: PT. Bin & Karya Prima & $(2016)$ & &
\end{tabular}

Sumber : PT. Bina Karya Prima (2016)

Berdasarkan data pergantian tingkat pergantian karyawan untuk tahun karyawan pada Tabel 1 maka didapatkan 2016 adalah:

$$
\begin{aligned}
\text { Turnover Rate } & =\frac{\text { Employee Separations For The Period }}{\text { Average Number of Employees During The Period }} \\
& =\frac{15}{(97+105) \div 2} \\
& =\quad \frac{15}{101} \quad=14,85 \%=15 \% \\
& =0,1485(\times 100 \%) \quad=15 \%
\end{aligned}
$$


Dapat dilihat bahwa tingkat pergantian karyawan di PT. Bina Karya Prima cabang Marunda untuk periode tahun 2016 adalah sebesar 15\%. Perputaran (turnover) karyawan merupakan pengunduran diri permanen dari suatu organisasi secara sukarela maupun tidak sukarela (Robbins, 2010, p36). Niatan berhenti kerja (turnover intentions) didefinisikan sebagai probabilitas yang sudah diperkirakan individu itu sendiri untuk meninggalkan organisasi secara permanen di masa depan (Shih dan Susanto, 2010). Keluar-masuknya karyawan akan menambah biaya rekrutmen, seleksi dan pelatihan sekaligus gangguan kerja. Setiap perusahaan memiliki standar tingkat pergantian karyawan yang berbeda-beda, namun jika tingkat pergantian karyawan mencapai lebih dari $10 \%$ per tahun maka dapat dikatakan tingkat pergantian karyawan tersebut tergolong tinggi (Harris dan Cameron, 2005). Dari pemaparan di atas, dapat disimpulkan bahwa PT. Bina Karya Prima memiliki tingkat pergantian karyawan yang tergolong cukup tinggi. Ketika tingkat pergantian karyawan dalam suatu perusahaan tergolong tinggi, tentu niat untuk meninggalkan organisasi (turnover intentions) karyawan juga tinggi. Peneliti tertarik untuk meneliti apa yang memengaruhi tingginya tingkat niat karyawan untuk meninggalkan organisasi pada PT. Bina Karya Prima cabang Marunda.

Berdasarkan

penelitian sebelumnya, terdapat dua faktor utama penyebab niatan karyawan untuk berhenti kerja, yaitu; kepuasan kerja dan tekanan pekerjaan (Kim dan Yoo, 2014). Karyawan yang puas memiliki tingkat niatan untuk berhenti yang lebih rendah, sedangkan karyawan yang tidak puas memiliki tingkat niatan untuk berhenti yang lebih tinggi (Robbins, 2010, p38). Kepuasan individu atas suatu pekerjaan terdiri dari pencapaian perubahan dan peningkatan, serta peningkatan pertumbuhan diri mereka yang memiliki implikasi penting pada perilaku individu di tempat kerja yang memengaruhi keinginan mereka untuk melanjutkan pekerjaan mereka dan keterlibatan mereka dalam pekerjaan, serta hubungan dengan rekan kerja lainnya.

Tett dan Meyer melakukan metaanalisis yang mencakup 178 sampel dari 155 studi terkait, dan mereka menemukan bahwa kepuasan kerja memiliki hubungan negatif terhadap niatan karyawan untuk berhenti kerja (Valentine et al., 2011). Penelitian lainnya yang dilakukan oleh Jaramillo et al. (2006), Jones et al., (1996) dan Egan et al., (2004) juga menemukan adanya hubungan negatif antara kepuasan kerja dengan niatan berhenti kerja dalam konteks organisasi yang berbeda (Valentine et al., 2011). Dan penelitian ini juga menguji pengaruh negatif kepuasan kerja terhadap niatan karyawan untuk berhenti kerja.

Secara teoritis, selain kepuasan kerja, niat berhenti kerja juga dapat dipengaruhi oleh kinerja karyawan. Berdasarkan beberapa hasil penelitian terdahulu terdapat pengaruh negatif kinerja karyawan terhadap niat berhenti kerja, dimana karyawan dengan kinerja yang lebih tinggi cenderung akan tetap bertahan pada organisasi dibandingkan dengan karyawan yang kinerjanya rendah (Bycio et al., 1990; Griffeth et al., 2000; McEvoy dan Cascio, 1987; Williams dan Livingstone, 1994; Laschober dan Eby, 2013). Cukup banyak penelitian yang telah menguji pengaruh kinerja karyawan terhadap niatan berhenti kerja, namun sifat dan arah pengaruh ini berbeda-beda. Misalnya beberapa studi menunjukkan keterhubungan negatif antara kinerja karyawan dan niatan berhenti kerja (misalnya; Trevor et al., 1997), sedangkan Martin et al. (1981) menunjukkan adanya keterhubungan positif. Namun penelitian ini menguji apakah terdapat pengaruh negatif dan signifikan kinerja karyawan terhadap niatan berhenti kerja.

Secara teoritis, dengan adanya kepuasan kerja yang dirasakan oleh karyawan juga dapat berpengaruh terhadap kinerja karyawan itu sendiri. Karyawan yang merasa puas akan lebih produktif dan kreatif (Muindi dan K'Obonyo, 2015). Kepuasan kerja dapat menciptakan tingkat 
motivasi yang tinggi dalam diri karyawan, hal ini dapat meningkatkan kinerja karyawan dalam organisasi (Suma dan Lesha, 2013). Seseorang dengan kepuasan kerja yang tinggi memiliki sikap positif terhadap pekerjaannya (Robbins, 2010, p37).

$\begin{array}{cr}\text { Berdasarkan } & \text { penelitian } \\ \text { sebelumnya, keterhubungan } & \text { antara }\end{array}$
kepuasan kerja dan kinerja karyawan masih belum jelas (Muindi dan K'Obonyo, 2015). Hal ini ditunjukkan oleh penelitian yang dilakukan oleh Iaffaldano dan Muchinsky yang menemukan adanya keterhubungan yang lemah (Muindi dan K'Obonyo, 2015). Selain itu, Crossman dan Abou-Zaki dalam penelitian mereka terhadap karyawan bank di Lebanon tidak menemukan adanya pengaruh yang signifikan antara kepuasan kerja dengan kinerja karyawan (Muindi dan K'Obonyo, 2015). Namun, tidak sedikit pula peneliti yang menemukan adanya pengaruh yang positif antara kepuasan kerja dengan kinerja karyawan, misalnya Edwards dan Bell (2008), Hira dan Waqas (2012), Iqbal et al. (2012), Chen dan Liu, (2012), dan Fu dan Deshpande (2014). Penelitian ini menguji apakah terdapat pengaruh positif kepuasan kerja terhadap kinerja karyawan.

Agar sebuah organisasi dapat menjadi sukses mereka harus terus-menerus memastikan kepuasan kerja karyawan mereka (Olusegun, 2013). Terdapat beberapa komponen yang dianggap penting untuk kepuasan kerja, karena komponen tersebut memengaruhi cara seseorang berfikir/mempersepsi tentang pekerjaannya saat ini. Komponen ini meliputi: gaji/ upah, promosi, manfaat yang didapat, atasan, rekan kerja, kondisi kerja, komunikasi, keamanan, produktivitas, dan pekerjaan itu sendiri (Olusegun, 2013).

Setiap organisasi atau perusahaan memerlukan sumber daya manusia untuk mencapai tujuannya. Sumber daya merupakan sumber energi, tenaga, kekuatan yang diperlukan untuk menciptakan daya, gerakan, aktivitas, kegiatan dan tindakan. Sumber daya tersebut antara lain terdiri atas sumber daya alam, sumber daya finansial, sumber daya insani, sumber daya ilmu pengetahuan, dan sumber daya teknologi. Di antara semua sumber daya tersebut, sumber daya yang terpenting adalah sumber daya insani (SDI). SDI merupakan sumber daya yang digunakan untuk menggerakkan dan menyinergikan sumber daya lainnya demi mencapai tujuan organisasi. Tanpa SDI, sumber daya lainnya kurang bermanfaat dalam mencapai tujuan organisasi (Wirawan, 2015), sebab manusia itu sendiri yang mengendalikan yang lain. Manusia memilih teknologi, manusia yang mencari modal, manusia yang menggunakan dan memeliharanya, di samping itu manusia juga adalah salah satu sumber keunggulan daya saing lestari perusahaan (Hariandja, 2002).

Besarnya peranan SDI dalam sebuah organisasi dikategorikan sebagai salah satu aset terpenting bagi perusahaan dalam upaya memperoleh keuntungan demi keberlangsungan sebuah organisasi. Mengingat pentingnya peran dan fungsi SDI dalam pembentukan nilai tambah atas sumber daya organisasi, maka diperlukan pendayagunaan sumber daya secara efektif dan efisien (Mamik dan Syarif, 2016). Keberhasilan setiap organisasi sangat tergantung pada bagaimana menarik calon karyawan, memotivasi, dan mempertahankan tenaga kerja yang berkinerja tinggi (Muindi dan K'Obonyo, 2015).

Persaingan antar organisasi mengharuskan mereka memberikan perhatian lebih pada efektivitas operasional untuk keunggulan kompetitif. Efektivitas untuk keunggulan kompetitif terutama tergantung pada kinerja karyawan (Muindi dan K'Obonyo, 2015). Untuk mencapai kesuksesan suatu organisasi, perlu perhatian untuk mengatasi kebutuhan karyawan, terutama pada aspek-aspek seperti kualitas kehidupan kerja dan faktor-faktor lain yang dapat berdampak pada kinerja karyawan (Muindi dan K'Obonyo, 2015).

Dalam arti luas, kualitas kehidupan kerja (quality of work life) merupakan total dari jumlah nilai-nilai, baik material mau pun nirmaterial yang diperoleh oleh seorang 
pekerja sepanjang kehidupan karirnya. Winter et al. (2000) melihat kualitas kehidupan kerja sebagai tanggapan sikap terhadap lingkungan kerja yang berlaku. Kualitas kehidupan kerja mencakup aspek yang berhubungan dengan kehidupan kerja, seperti upah dan jam kerja, lingkungan kerja, manfaat dan layanan, prospek karir dan hubungan manusia, yang mungkin relevan dengan kepuasan pekerja. Kualitas kehidupan kerja dianggap sebagai strategi untuk meningkatkan kualitas kehidupan kerja karyawan dengan tujuan untuk memuaskan baik tujuan organisasi maupun kebutuhan karyawan itu sendiri (Muindi dan K’Obonyo, 2015).

Ketika kebutuhan-kebutuhan manusia terpenuhi, maka individu tersebut akan merasa puas. Hal ini ditunjukan oleh pernyataan Cascio (1998), bahwa kualitas kehidupan kerja berkaitan dengan sejauh mana berbagai kebutuhan manusia terpenuhi. Karyawan akan merasa lebih puas ketika mereka menikmati lingkungan kerja tempat mereka bekerja (Muindi dan K'Obonyo, 2015). Dressel berpandangan bahwa ketidakpuasan kerja disebabkan oleh kondisi kerja yang tidak memadai (Hasanmoradi, 2011). Menurut Crane dan Iwanicki lingkungan kerja karyawan, beban kerja yang seimbang, hubungan dengan rekan kerja, faktor pribadi, gaji dan tunjangan, serta profesionalisme dan latar belakang budaya karyawan memengaruhi kepuasan kerja mereka (Hasanmoradi, 2011). Bearfield meneliti kualitas kehidupan kerja di antara karyawan Australia. Studi ini menemukan tingkat kepuasan kerja yang berbeda dalam beberapa aspek seperti gaji, beban kerja, tekanan kerja, jenis pekerjaan, hubungan antar rekan kerja, dan aspek lainnya antara kelompok-kelompok yang berbeda (Muindi dan K'Obonyo, 2015). Di sisi lain, Ganguly dalam studi kualitas kehidupan kerja dan kepuasan kerja karyawan di universitas India menyimpulkan bahwa kualitas kehidupan kerja secara positif dan signifikan berkontribusi terhadap peningkatan kepuasan kerja karyawan dalam pekerjaan mereka sekarang (Muindi dan K'Obonyo, 2015). Penelitian ini juga menguji pengaruh positif kualitas kehidupan kerja terhadap kepuasan kerja karyawan.

Faktor-faktor dalam kualitas kehidupan kerja juga dapat memengaruhi kinerja karyawan. Hal ini di buktikan oleh penelitian yang dilakukan oleh Hardin yang menemukan bahwa lingkungan kerja memiliki pengaruh terhadap kinerja karyawan (Majumdar et al., 2012). Menurut Darlene dan Borman lingkungan kerja seperti hubungan dengan rekan kerja, kepuasan kerja dan pengawasan manajemen dapat mengembangkan kinerja karyawan (Majumdar et al., 2012). Kualitas kehidupan kerja secara langsung berkaitan dengan luaran (output) yang dihasilkan oleh individu (Majumdar et al., 2012). Perbedaan aspek remunerasi yang diterima oleh karyawan dapat memengaruhi kepuasan kerja dan kinerja karyawan (Majumdar et al., 2012). Studi yang dilakukan oleh Wan (2007) dan Matzler \& Renzl (2007) membuktikan bahwa remunerasi merupakan faktor signifikan yang menjamin kinerja terbaik dari organisasi, terutama kinerja karyawan itu sendiri (Majumdar et al., 2012). Kualitas kehidupan kerja memotivasi karyawan untuk memperoleh pengetahuan yang diinginkan, keterampilan dan keahlian yang dibutuhkan untuk mencapai ekspektasi kinerja dengan mengatasi nilai-nilai, sikap dan keyakinan dari karyawan yang diperlukan untuk melakukan perannya saat ini (Majumdar et al., 2012). Penelitian ini juga menguji pengaruh positif kualitas kehidupan kerja terhadap kinerja karyawan.

Berdasarkan fenomena, celah teori dan celah penelitian sebagaimana telah dipaparkan di atas, maka penelitian ini dilakukan untuk membuktikan "PENGARUH KUALITAS KEHIDUPAN KERJA TERHADAP NIATAN BERHENTI KERJA DENGAN MEDIASI KEPUASAN KERJA DAN KINERJA KARYAWAN." 
Berdasarkan latar belakang masalah yang telah diuraikan, maka dapat dirumuskan persoalan-persoalan penelitian seperti berikut ini:

1. Apakah niatan berhenti kerja karyawan PT. Bina Karya Prima cabang Marunda dipengaruhi oleh kepuasan kerja?

2. Apakah niatan berhenti kerja karyawan PT. Bina Karya Prima cabang Marunda dipengaruhi oleh kinerja karyawan?

3. Apakah kinerja karyawan pada PT. Bina Karya Prima cabang Marunda dipengaruhi oleh kepuasan kerja karyawan?

4. Apakah kepuasan kerja karyawan pada PT. Bina Karya Prima cabang Marunda dipengaruhi oleh kualitas kehidupan kerja?

5. Apakah kinerja pada karyawan PT. Bina Karya Prima cabang Marunda dipengaruhi oleh kualitas kehidupan kerja?

\section{TINJAUAN PUSTAKA}

\section{Niatan Berhenti Kerja}

Perputaran karyawan merupakan pengunduran diri permanen dari suatu organisasi secara sukarela maupun tidak sukarela (Robbins, 2010, p36). Niatan berhenti kerja (turnover Intentions) adalah hasrat atau keinginan secara sadar dan terencana untuk meninggalkan suatu organisasi (Hofaidhllaoui dan Chhinzer, 2014). Vandenberg dan Nelson mendefinisikan niatan berhenti kerja sebagai probabilitas yang sudah diperkirakan individu itu sendiri untuk meninggalkan organisasi secara permanen di masa depan (Shih dan Susanto, 2010).

\section{Kepuasan Kerja}

Kepuasan kerja adalah keadaan emosi positif atau menyenangkan yang dihasilkan dari penilaian suatu pekerjaan atau pengalaman kerja seseorang atau sikap dan perasaan yang dimiliki seseorang mengenai pekerjaan mereka (Muindi dan K'Obonyo, 2015). Kepuasan kerja adalah evaluasi yang menggambarkan seseorang atas perasaan sikap senang atau tidak senang, puas atau tidak puas dalam bekerja (Rivai dan Sagala, 2009). Vroom mendefinisikan kepuasan kerja sebagai orientasi positif dari seorang individu terhadap peran yang saat ini ia duduki (Suma dan Lesha, 2013). Kepuasan kerja didefinisikan sebagai keadaan emosi positif yang dihasilkan dari penilaian situasi pekerjaan seseorang dan hal tersebut berkaitan dengan karakteristik dan tuntutan atau kebutuhan pekerjaan seseorang (Hasanmoradi, 2011).

\section{Kinerja Karyawan}

Kinerja adalah luaran yang dihasilkan oleh fungsi-fungsi atau indikator-indikator suatu pekerjaan atau suatu profesi dalam waktu tertentu (Wirawan, 2015). Kinerja karyawan merupakan variabel individu yang membedakan antara kinerja karyawan dari kinerja organisasi (Muindi dan K'Obonyo, 2015). Menurut Borman dan Motowidlo, kinerja karyawan adalah kemampuan individu dalam melakukan aktivitas kerja yang berkontribusi secara langsung mau pun tidak langsung terhadap organisasi (Muindi dan K'Obonyo, 2015). Kinerja karyawan terdiri dari 3 komponen, yaitu; focal performance, contextual performance, dan withdrawal behavior (Veerasamy et al., 2013). Focal performance didefinisikan sebagai sejauh mana karyawan memenuhi atau melebihi harapan atas persyaratan peran tugas yang dibutuhkan. Contextual performance didefinisikan sebagai peran ekstra, perilaku individu yang bebas (discretionary behavior) oleh para karyawan di tempat kerja yang tidak secara formal menjadi bagian spesifik dari peran fokal, atau lebih diarahkan pada dukungan bagi organisasi atau membantu orang lain. Withdrawal behavior didefinisikan sebagai perilaku diskresioner karyawan di tempat kerja yang ditunjukkan dengan keterlambatan, absensi, atau keluar masuk karyawan (Veerasamy et al., 2013). 


\section{Kualitas Kehidupan Kerja}

Secara umum, kualitas kehidupan kerja (quality of work life) mengacu pada seberapa menguntungkan atau tidak menguntungkannya berbagai aspek dari pekerjaan itu sendiri serta lingkungan kerjanya (Sadri dan Goveas, 2013). Kualitas kehidupan kerja dapat didefinisikan dengan dua cara, yakni; sebagai satu perangkat kondisi obyektif organisasi dan praktik-praktik dalam organisasi (kompensasi dan penghargaan, lingkungan kerja, keamanan kerja, dll) atau sebagai persepsi karyawan bahwa mereka merasa aman, relatif puas, dan dapat tumbuh serta berkembang sebagai manusia (Cascio, 1998). Cascio (1998) juga mengatakan bahwa kualitas kehidupan kerja berkaitan dengan sejauh mana berbagai kebutuhan manusia terpenuhi. Lau mendefinisikan kualitas kehidupan kerja sebagai suatu kondisi yang menguntungkan dan lingkungan kerja yang mendukung dan mempromosikan kepuasan karyawan dengan menyediakan keamanan kerja dan penghargaan (Muindi dan K'Obonyo, 2015). Lawler mendefinisikan kualitas kehidupan kerja sebagai persepsi karyawan mengenai kesejahteraan fisik dan mental mereka di tempat kerja (Muindi dan K’Obonyo, 2015). Kualitas kehidupan kerja juga dapat didefinisikan sebagai lingkungan kerja karyawan yang menguntungkan secara keseluruhan yang menumbuhkan, memperkuat serta memelihara kepuasan dengan menyediakan imbalan yang memadai, keamanan kerja yang layak dan peluang pengembangan karir bagi karyawan (Sadri dan Goveas, 2013).

\section{Pengaruh Kepuasan Kerja Terhadap Niatan Berhenti Kerja}

Mobley mengaitkan niatan berhenti kerja dengan kepuasan kerja karyawan dan kualitas hubungan kerja dengan organisasi mereka (Hofaidhllaoui dan Chhinzer, 2014). Kepuasan kerja yang rendah adalah salah satu faktor yang memengaruhi niat untuk meninggalkan organisasi dan untuk pensiun dini (Muindi dan K'Obonyo, 2015). Berdasarkan penelitian Syptak et al.,
(1999) karyawan yang merasa puas dengan pekerjaan mereka cenderung lebih memiliki komitmen terhadap organisasi, yang secara tidak langsung juga berhubungan dengan niatan berhenti kerja. Ketika karyawan berkomitmen terhadap organisasi, maka akan berdampak pada niat karyawan untuk meninggalkan organisasi sekarang menjadi lebih rendah. Sebaliknya, Moser (1997) menyatakan bahwa rendahnya tingkat kepuasan kerja karyawan sangat penting karena dapat mengarahkan pada kelesuan dan mengurangi komitmen organisasi. Jamal (1997) menyatakan bahwa rendahnya kepuasan kerja merupakan prediktor dari berhentinya seseorang dari pekerjaan, dan hal tersebut secara langsung dapat memengaruhi niatan berhenti kerja karyawan pada organisasi. Tett dan Meyer melakukan meta-analisis yang mencakup 178 sampel dari 155 studi terkait, dan mereka menemukan bahwa kepuasan kerja memiliki hubungan negatif terhadap niatan berhenti kerja (Valentine et al., 2011). Penelitian lainnya yang dilakukan oleh Jaramillo et al. (2006), Jones et al., (1996) dan Egan et al., (2004) juga menemukan adanya keterhubungan negatif antara kepuasan kerja dengan niatan berhenti kerja dalam konteks organisasi yang berbeda (Valentine et al., 2011).

H1: Terdapat pengaruh negatif antara kepuasan kerja terhadap niatan berhenti kerja.

\section{Pengaruh Kinerja Karyawan Terhadap Niatan Berhenti Kerja}

Beberapa penelitian sebelumnya seperti yang dilakukan oleh Bycio et al. (1990), Griffeth et al. (2000), McEvoy dan Cascio (1987), Williams dan Livingstone (1994), Trevor et al. (1997) dan Laschober dan Eby (2013) membuktikan bahwa karyawan dengan kinerja yang lebih tinggi cenderung akan tetap bertahan pada organisasi dibandingkan dengan karyawan yang kinerjanya rendah. Dengan kata lain, ketika kinerja karyawan meningkat maka kecendrungan niat untuk meninggalkan pekerjaan/organisasi akan rendah, begitu pula sebaliknya. Namun, ada juga 
penelitian yang menunjukkan adanya keterhubungan yang lemah bahkan tidak signifikan antara kinerja karyawan dengan niatan berhenti kerja. Penelitian yang dilakukan oleh Lai dan Chen (2012) menunjukkan tidak adanya keterhubungan yang signifikan antara kinerja karyawan dengan niatan berhenti kerja.

H2: Terdapat pengaruh negatif antara kinerja karyawan terhadap niatan berhenti kerja.

\section{Pengaruh Kepuasan Kerja Terhadap Kinerja Karyawan}

Berdasarkan penelitian-penelitian sebelumnya, keterhubungan antara kepuasan kerja dan kinerja karyawan masih belum jelas, dengan demikian tidak dapat diasumsikan bahwa kepuasan kerja akan meningkatkan kinerja karyawan, atau individu yang berkinerja tinggi pasti puas dengan pekerjaan mereka (Muindi dan K'Obonyo, 2015). Petty et al. menemukan bahwa keterhubungan antara kepuasan dan kinerja dapat beroperasi secara berbeda pada jenis atau tingkatan karyawan yang berbeda pula (Muindi dan K'Obonyo, 2015). Kemudian dalam meta-analisis dari keterhubungan yang sama, yang dilakukan oleh Iaffaldano dan Muchinsky menemukan adanya keterhubungan yang lemah (Muindi dan K'Obonyo, 2015). Selain itu, Crossman dan Abou-Zaki (2003) dalam penelitian mereka terhadap karyawan bank di Libanon tidak menemukan adanya keterhubungan yang signifikan antara kepuasan kerja dengan kinerja karyawan. Di sisi lain, Hira dan Waqas (2012) menemukan adanya keterhubungan yang positif antara kepuasan kerja dengan kinerja karyawan. Iqbal et al., (2012) juga menemukan bahwa kepuasan kerja memiliki pengaruh positif terhadap kinerja karyawan. Selain itu, Chen dan Liu (2012), juga membuktikan bahwa kinerja karyawan di Taiwan dipengaruhi secara positif oleh kepuasan kerja. Karyawan yang merasa puas akan lebih produktif dan kreatif (Syptak et al., 1999; Muindi dan K'Obonyo, 2015). Edwards dan Bell (2008) menemukan keterhubungan yang positif dan signifikan antara kepuasan dengan kinerja karyawan. Kepuasan kerja dapat menciptakan tingkat motivasi yang tinggi dalam diri karyawan, sehingga hal ini dapat meningkatkan kinerja karyawan dalam organisasi (Suma dan Lesha, 2013).

H3: Terdapat pengaruh positif antara kepuasan kerja terhadap kinerja karyawan.

\section{Pengaruh Kualitas Kehidupan Kerja Terhadap Kepuasan Kerja Kualitas kehidupan kerja secara signifikan berpengaruh terhadap} peningkatan kepuasan atau ketidakpuasan karyawan dalam pekerjaan mereka (Muindi dan K'Obonyo, 2015). Kualitas kehidupan kerja didasarkan pada teori kebutuhan Maslow, Herzbeg dan McGregor memiliki kesesuaian dengan faktor-faktor yang digunakan dalam kualitas kehidupan kerja (Sadri dan Goveas, 2013). Ketika kebutuhan-kebutuhan manusia terpenuhi maka individu tersebut akan merasa puas. Hal ini ditunjukkan oleh pernyataan Cascio (1998), bahwa kualitas kehidupan kerja berkaitan dengan sejauh mana berbagai kebutuhan manusia terpenuhi. Mirvis dan Lawler (1984) menemukan fakta bahwa kualitas kehidupan kerja berhubungan dengan kepuasan yang mengacu pada elemen dasar kualitas kehidupan kerja seperti; upah yang adil, kondisi kerja, lingkungan kerja yang aman, kesempatan kerja dan kesempatan untuk tumbuh serta berkembang. Karyawan akan merasa lebih puas ketika mereka menyukai lingkungan tempat dimana ia bekerja (Muindi dan K'Obonyo, 2015). Crane dan Iwanicki juga menemukan bahwa faktor-faktor dalam kualitas kehidupan kerja seperti yang telah disebutkan di atas memengaruhi kepuasan kerja (Hasanmoradi, 2011). Hubungan dengan rekan kerja dan dukungan dari atasan memiliki kontribusi dalam menciptakan kepuasan kerja karyawan (Bilimoria et al., 2006), begitu pun menurut Van Ruysseveldt, dengan peluang untuk tumbuh dan berkembang melalui pendidikan sangat terkait dengan kepuasan kerja karyawan (Bos et al.,2009). 
H4: Terdapat pengaruh positif antara kualitas kehidupan kerja terhadap kepuasan kerja.

\section{Pengaruh Kualitas Kehidupan Kerja Terhadap Kinerja Karyawan}

Literatur menunjukkan adanya keterhubungan antara kualitas kehidupan kerja dengan kinerja karyawan. Kurt Lewin dalam teori perilaku karyawan menunjukkan adanya keterhubungan antara kualitas kehidupan kerja dengan kinerja karyawan. Berdasarkan teori ini, perilaku individu dipengaruhi oleh bagaimana seseorang mempersepsikan dan bereaksi terhadap lingkungan yang ada dalam organisasi, yang dalam penelitian ini dapat dikatakan sebagai kualitas lingkungan kehidupan kerja (Muindi dan K'Obonyo, 2015). Aspek remunerasi seperti upah, kenaikan upah, bonus, tunjangan pensiun, dan tunjangan kesehatan telah terbukti mendorong karyawan untuk memberikan yang terbaik kepada organisasi mereka (Muindi dan K'Obonyo, 2015), begitu pun dengan aspek lingkungan kerja yang aman juga telah dibuktikan memiliki kontribusi positif terhadap kinerja karyawan (Borman et al., 1991; Kim et al., 1999; Muindi dan K'Obonyo, 2015). Kualitas kehidupan kerja membentuk karyawan yang lebih sehat, puas dan produktif, yang pada akhirnya akan memberikan/menciptakan efisiensi dan menguntungkan organisasi melalui kinerja karyawan yang lebih optimal (Majumdar et al., 2012).

H5: Terdapat pengaruh positif antara kualitas kehidupan kerja terhadap kinerja karyawan.

\section{Rerangka Konseptual}

Berdasarkan proposisi-proposisi di atas, maka dapat dibangun rerangka konseptual seperti pada Gambar 1.

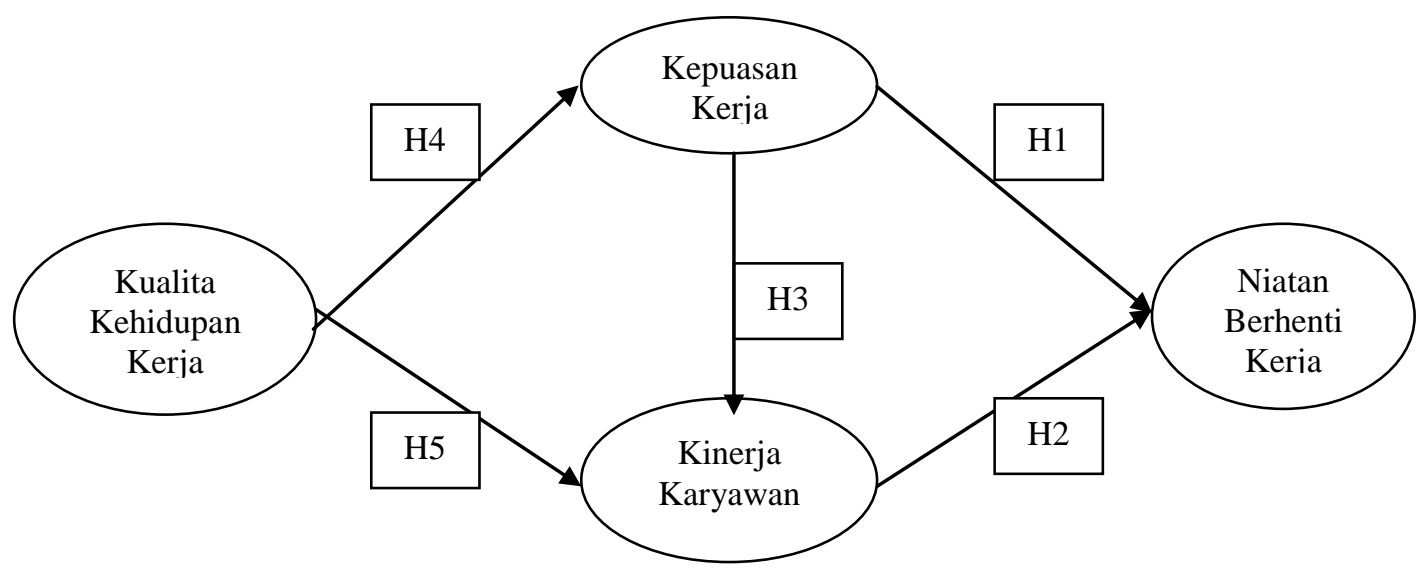

Gambar 1. Rerangka Konseptual

Sumber: Integrasi model Muindi dan K'Obonyo (2015) dan Lai dan Chen (2012)

\section{METODE}

\section{Populasi dan Sampel}

Populasi penelitian adalah seluruh karyawan pada PT. Bina Karya Prima cabang Marunda yang berjumlah 103 orang. Perusahaan tersebut terletak di $\mathrm{Jl}$. Semarang Blok A6 No. 4, KBN Marunda, Cilincing, Jakarta Utara. Dengan menggunakan teknik saturation sampling (teknik sampel jenuh) dimana semua anggota populasi dijadikan sampel, maka sampel penelitian ini adalah keseluruhan populasi, yaitu sebanyak 103 orang karyawan. 


\section{Responden Penelitian}

Responden pada penelitian ini berjumlah 103 karyawan di PT. Bina Karya
Prima cabang Marunda. Data profil responden dapat dilihat pada Tabel 2.

Tabel 2. Profil Responden

\begin{tabular}{cc|c|c}
\hline \multicolumn{1}{c|}{ Karakteristik Responden } & Jumlah & Persentase \\
Gender & Laki - Laki & 84 & 82 \\
& Perempuan & 19 & 18 \\
Tingkat Pendidikan & SMP & 0 & 0 \\
& SMA/ K & 77 & 75 \\
& D3 & 5 & 5 \\
S1 & 21 & 20 \\
Lama Bekerja & S2 & 0 & 0 \\
& 1 Tahun & 5 & 5 \\
& 1-2 Tahun & 59 & 57 \\
Jabatan & $>2$ Tahun & 39 & 38 \\
& Staff & 93 & 90 \\
& SPV & 10 & 10 \\
\hline
\end{tabular}

Sumber: Data Primer Berdasarkan Hasil Kuesioner (2016)

\section{Skala Pengukuran}

Skala pengukuran (measurement scale) untuk peubah kualitas kehidupan kerja diadaptasi 17 butir yang dikembangkan oleh Sadri \& Goveas (2013). Skala pengukuran kepuasan kerja menggunakan 13 butir yang dikembangkan oleh Cellucci \& DeVries (1978). Untuk mengukur kinerja karyawan menggunakan 8 butir dari skala pengukuran yang dikembangkan oleh Barlow dan Hainsworth (2001). Peubah niatan berhenti kerja diukur dengan 3 butir dari skala pengukuran yang dikembangkan oleh Hom \& Griffeth (1991).

\section{Teknik Analisis Data}

Teknik analisis data yang digunakan dalam penelitian ini adalah Structural Equation Modeling (SEM), yaitu sebuah teknik analisis statistika multivariat yang digunakan untuk menguji keterhubungan yang rumit antar beberapa peubah. Analisis multivariat adalah analisis statistika yang melibatkan lebih dari dua variabel dalam penelitian. SEM sering digunakan karena bisa melakukan analisis secara sistematis dan menyeluruh akan sebuah model. SEM akan mengukur secara langsung sederetan persamaan yang berdiri sendiri, namun saling memiliki ketergantungan dalam sebuah model struktural.

Lebih spesifik, penelitian ini menggunakan Partial Least Squares (PLS) yang merupakan salah satu bagian dari SEM yang memumpun pada analisis varians. Pada hasil penelitian akan diberikan interpretasi dari hasil uji outer model dan inner model menggunakan PLSSEM ini. Outer model merupakan spesifikasi keterhubungan antar peubah laten dan indikatornya, sering disebut uji indikator (kesahihan) dan uji kehandalan, yaitu dengan melihat nilai dari Convergent Validity, Discriminant Validity atau AVE, dan Composite Reliability. Inner model merupakan spesifikasi keterhubungan antar peubah laten, sering disebut uji hipotesis. 


\section{HASIL PENELITIAN DAN BAHASAN}

\section{Uji Kesahihan dan Kehandalan}

Tabel 3 menunjukkan bahwa seluruh indikator (outer loading) memiliki nilai > 0,70, sehingga dapat disimpulkan bahwa seluruh indikator dinyatakan sahih. Tabel 3 juga menunjukkan bahwa nilai AVE dari setiap peubah > 0,50, dengan demikian juga dapat dikatakan bahwa semua peubah dinyatakan sahih. Selanjutkan dari segi kehandalan, Tabel 3 menunjukkan bahwa nilai Composite Reliability dan Cronbach's Alpha dari setiap peubah >0.70, sehingga dapat disimpulkan bahwa semua peubah dinyatakan handal.

\section{Hasil Uji Hipotesis dan Bahasan}

Hasil pengujian pengaruh kepuasan kerja terhadap niatan berhenti kerja terbukti berpengaruh negatif dan signifikan dengan nilai T-statistik lebih dari 1,96 (4,274 > 1,96). Penelitian ini mendukung penelitian sebelumnya yang dilakukan oleh Tett dan Meyer (1993), Jones et al., (1996), Egan et al., (2004), Jaramillo et al. (2006) dan Valentine et al., (2011) yang menemukan adanya keterhubungan negatif antara kepuasan kerja dengan niatan berhenti kerja. Kepuasan individu atas suatu pekerjaan terdiri dari pencapaian perubahan dan peningkatan, serta peningkatan pertumbuhan diri mereka dan memiliki implikasi penting pada perilaku individu di tempat kerja yang memengaruhi keinginan mereka untuk tetap bekerja atau melanjutkan pekerjaan mereka dan keterlibatan mereka dalam pekerjaan (Hasanmoradi, 2011).

Tabel 3. PLS Outer Model

\begin{tabular}{lrrrr}
\hline \multicolumn{1}{c}{ Items } & $\begin{array}{c}\text { Outer } \\
\text { Loadings }\end{array}$ & $\begin{array}{c}\text { Convergent } \\
\text { validity }\end{array}$ & $\begin{array}{r}\text { Cronbach's } \\
\text { Alpha }\end{array}$ & $\begin{array}{c}\text { Composite } \\
\text { Reliability }\end{array}$ \\
\hline Kualitas Kehidupan Kerja & 0,780 & & & \\
QWL1 & 0,758 & & 0,962 \\
QWL2 & 0,830 & & & \\
QWL3 & 0,806 & & \\
QWL4 & 0,756 & & \\
QWL5 & 0,776 & & \\
QWL6 & 0,822 & & \\
QWL7 & 0,831 & & \\
QWL8 & 0,712 & & & \\
QWL9 & 0,797 & & & \\
QWL10 & 0,711 & & & \\
QWL11 & 0,727 & & & \\
QWL12 & 0,766 & & & \\
QWL13 & 0,831 & & & \\
QWL14 & 0,796 & & \\
QWL15 & 0,719 & & & \\
QWL16 & 0,709 & & \\
QWL17 & & AVE=0,643 & & \\
Kepuasan Kerja & 0,721 & & & \\
JS1 & 0,720 & & & \\
JS2 & 0,763 & & & \\
JS3 & 0,890 & & & \\
JS4 & 0,772 & & & \\
JS5 & & & & \\
\hline
\end{tabular}




\begin{tabular}{|c|c|c|c|c|}
\hline Items & $\begin{array}{c}\text { Outer } \\
\text { Loadings }\end{array}$ & $\begin{array}{c}\text { Convergent } \\
\text { validity }\end{array}$ & $\begin{array}{r}\text { Cronbach's } \\
\text { Alpha }\end{array}$ & $\begin{array}{l}\text { Composite } \\
\text { Reliability }\end{array}$ \\
\hline JS6 & 0,768 & & & \\
\hline JS7 & 0,782 & & & \\
\hline JS8 & 0,825 & & & \\
\hline JS10 & 0,870 & & & \\
\hline JS11 & 0,808 & & & \\
\hline JS12 & 0,826 & & & \\
\hline JS13 & 0,825 & & & \\
\hline Kinerja Karyawan & & $\mathrm{AVE}=0,594$ & 0,965 & 0,967 \\
\hline JP1 & 0,771 & & & \\
\hline JP2 & 0,795 & & & \\
\hline JP3 & 0,734 & & & \\
\hline JP4 & 0,747 & & & \\
\hline JP5 & 0,717 & & & \\
\hline JP6 & 0,740 & & & \\
\hline JP7 & 0,728 & & & \\
\hline JP8 & 0,705 & & & \\
\hline JP9 & 0,868 & & & \\
\hline JP10 & 0,802 & & & \\
\hline JP11 & 0,783 & & & \\
\hline JP12 & 0,840 & & & \\
\hline JP13 & 0,798 & & & \\
\hline JP14 & 0,774 & & & \\
\hline JP15 & 0,771 & & & \\
\hline JP16 & 0,791 & & & \\
\hline JP17 & 0,775 & & & \\
\hline JP18 & 0,738 & & & \\
\hline JP19 & 0,763 & & & \\
\hline JP20 & 0,754 & & & \\
\hline Niatan Berhenti Kerja & & $\mathrm{AVE}=0,706$ & 0,794 & 0,878 \\
\hline TI1 & 0,884 & & & \\
\hline TI2 & 0,791 & & & \\
\hline TI3 & 0,843 & & & \\
\hline
\end{tabular}

Sumber: Hasil pengolahan data primer dengan SmartPLS 3.0 (2016)

Hasil pengujian pengaruh kinerja karyawan terhadap niatan berhenti kerja terbukti berpengaruh negatif dan signifikan dengan nilai T-statistik lebih dari 1,96 $(2,195>1,96)$. Penelitian ini mendukung penelitian terdahulu yang dilakukan oleh Trevor et al., (1997) yang menunjukkan adanya pengaruh negatif antara niatan berhenti kerja dan kinerja karyawan (Laschober dan Eby, 2013). Karyawan dengan kinerja yang lebih tinggi cenderung akan tetap bertahan berkerja pada organisasi dibandingkan dengan karyawan yang kinerjanya rendah (Bycio et al., 1990; Griffeth et al., 2000; McEvoy dan Cascio, 1987; Williams dan Livingstone, 1994; Laschober dan Eby, 2013). Karyawan yang memiliki kinerja yang tinggi dipandang sebagai aset serta keunggulan dari segi sumber daya manusia perusahaan, sehingga tentu perusahaan akan cenderung melakukan strategi retensi untuk mempertahankan karyawan tersebut. 
Tabel 4. Path Coefficients

\begin{tabular}{lrrr}
\hline & $\begin{array}{l}\text { Original } \\
\text { Sample (O) }\end{array}$ & T Statistics & P-values \\
Kepuasan Kerja -> Niatan Berhenti & $-0,361$ & 4,274 & 0,000 \\
Kinerja Karyawan-> Niatan Berhenti & $-0,288$ & 2,195 & 0,028 \\
Kepuasan kerja -> Kinerja Karyawan & $-0,030$ & 0,282 & 0,778 \\
Kualitas Kehidupan Kerja -> Kepuasan kerja & 0,120 & 0,829 & 0,407 \\
Kualitas Kehidupan Kerja -> Kinerja & 0,358 & 4,175 & 0,000 \\
Karyawan & & \\
\hline
\end{tabular}

Sumber: Hasil pengolahan data primer dengan SmartPLS 3.0 (2016)

Hasil pengujian pengaruh kepuasan kerja terhadap kinerja karyawan tidak terbukti berpengaruh signifikan dengan nilai T-statistik kurang dari $1,96(0,282<$ 1,96). Hal ini menunjukkan bahwa kepuasan kerja karyawan di PT. Bina Karya Prima cabang Marunda tidak berpengaruh signifikan terhadap kinerja karyawan. Penelitian ini mendukung penelitian terdahulu yang dilakukan oleh Crossman dan Abou-Zaki (2003). Hal ini didasarkan pada anggapan bahwa karyawan yang memiliki kepuasan kerja yang tinggi tidak dapat diasumsikan juga mengarahkan pada kinerja yang tinggi, dan sebaliknya karyawan yang berkinerja tinggi tidak dapat diasumsikan memiliki kepuasan yang tinggi juga (Muindi dan K'Obonyo, 2015). Selain itu, kinerja juga dapat dipengaruhi oleh peubah lainnya, seperti kemampuan dan karakteristik individu (termasuk kepribadian dan kompetensi) serta persepsi peran (Muindi dan K'Obonyo, 2015). Karakteristik kepribadian tersebut meliputi locus of control, dimana semakin seseorang berorientasi pada pengendalian internal (internal locus of control) semakin ia akan merasa bahwa kinerjanya akan mengarahkan pada hasil yang diinginkan dan sebaliknya (Muindi dan K'Obonyo, 2015).

Hasil pengujian pengaruh kualitas kehidupan kerja terhadap kepuasan kerja tidak terbukti berpengaruh signifikan dengan nilai $\mathrm{T}$-statistik kurang dari 1,96 $(0,829<1,96)$. Penelitian ini tidak mendukung penelitian-penelitian terdahulu yang menyebutkan adanya pengaruh yang positif dan signifikan antara kualitas kehidupan kerja terhadap kepuasan kerja (Sadri dan Goveas, 2013). Hal ini menunjukkan bahwa meski pun adanya kualitas kehidupan kerja yang diberikan perusahaan seperti fasilitas, kecukupan sumber daya dan kontrol yang tepat, kompensasi dan penghargaan, keamanan kerja, budaya dan iklim organisasi, hubungan dan kerjasama, kebebasan dalam bekerja, serta lingkungan kerja yang tergolong baik secara standar operasional perusahaan tidak menjamin terciptanya kepuasan kerja karyawan itu sendiri. Hal ini mungkin saja disebabkan oleh adanya perbedaan celah antar generasi angkatan kerja pada perusahaan, dimana mayoritas organisasi atau perusahaan di Indonesia saat ini pada aras manajemen atas dan manajemen tengah masih diisi oleh generasi X, generasi kelahiran tahun 19611980 (VanMeter et al., 2013). Angkatan kerja baru adalah dari kelompok generasi Y. Gen Y adalah mereka yang lahir dari tahun 1981-2000 (VanMeter et al., 2013). Mayoritas latar belakang usia karyawan PT. Bina Karya Prima cabang Marunda adalah berumur 20-27 tahun, dimana mayoritas dari mereka lahir pada tahun 1990-1997, sehingga dapat dikatakan mereka termasuk ke dalam generasi $\mathrm{Y}$ dalam angkatan kerja. Gen $\mathrm{Y}$ ingin pekerjaan yang menantang, kemampuan untuk menjadi kreatif, adanya ketentuan prosedur yang jelas, dan manajer yang terbuka dan positif, mereka juga ingin terlibat dalam tim yang memotivasi dan 
memiliki komitmen (Luscombe et al. 2013). Gen Y secara emosional membutuhkan loloh balik yang konstan dan pujian di tempat kerja (Luscombe et al. 2013), sehingga hal ini memengaruhi tingkat kepuasan kerja pada generasi $\mathrm{Y}$ terutama karyawan pada PT. Bina Karya Prima cabang Marunda.

Hasil pengujian pengaruh kualitas kehidupan kerja terhadap kinerja karyawan terbukti berpengaruh positif dan signifikan dengan nilai T-statistik lebih dari 1,96 $(4,175>1,96)$. Hal ini menunjukkan bahwa dengan adanya fasilitas, kecukupan sumber daya dan kontrol yang tepat, kompensasi dan penghargaan, keamanan kerja, budaya dan iklim organisasi, hubungan dan kerjasama, kebebasan dalam bekerja, serta lingkungan kerja yang baik dapat meningkatkan kinerja karyawan. Penelitian ini mendukung penelitian sebelumnya yang dilakukan oleh Majumdar et al., (2012) yang juga menemukan bahwa kualitas kehidupan kerja memiliki pengaruh positif dan signifikan terhadap kinerja karyawan. Kualitas kehidupan kerja memotivasi karyawan untuk memperoleh pengetahuan yang diinginkan, keterampilan dan keahlian yang dibutuhkan untuk mencapai ekspektasi kinerja yang diperlukan untuk melakukan perannya saat ini (Majumdar et al., 2012). Kualitas kehidupan kerja membentuk karyawan yang lebih sehat dan produktif, yang pada akhirnya akan memberikan/ menciptakan efisiensi dan menguntungkan organisasi melalui kinerja karyawan yang lebih optimal (Majumdar $e t$ al., 2012).

\section{SIMPULAN DAN SARAN}

\section{Simpulan}

Pertama, hasil penelitian menunjukkan bahwa niatan berhenti kerja karyawan pada PT. Bina Karya Prima cabang Marunda terbukti dipengaruhi secara negatif dan signifikant oleh kepuasan kerja karyawan.

$$
\text { Kedua, hasil penelitian }
$$
menunjukkan bahwa niatan berhenti kerja karyawan pada PT. Bina Karya Prima cabang Marunda terbukti dipengaruhi secara negatif dan signifikan oleh kinerja karyawan. Karyawan dengan kinerja yang lebih tinggi cenderung akan tetap bertahan pada organisasi dibandingkan dengan karyawan yang kinerjanya rendah.

Ketiga, hasil penelitian menunjukkan bahwa kinerja karyawan pada PT. Bina Karya Prima cabang Marunda tidak terbukti dipengaruhi secara signifikan oleh kepuasan kerja. Hal ini didasarkan pada asumsi bahwa karyawan yang memiliki kepuasan kerja yang tinggi tidak dapat secara otomatis diasumsikan juga mengarahkan pada kinerja yang tinggi, dan sebaliknya karyawan yang berkinerja tinggi tidak dapat diasumsikan memiliki kepuasan yang tinggi juga (Muindi dan K'Obonyo, 2015).

Keempat, hasil penelitian menunjukkan bahwa kepuasan kerja karyawan pada PT. Bina Karya Prima cabang Marunda tidak terbukti dipengaruhi secara signifikan oleh kualitas kehidupan kerja. Hal ini menunjukkan bahwa meskipun adanya kualitas kehidupan kerja yang diberikan perusahaan tidak menjamin terciptanya kepuasan kerja karyawan itu sendiri, terutama pada angkatan kerja generasi Y.

Kelima, hasil penelitian menunjukkan bahwa kinerja karyawan pada PT. Bina Karya Prima cabang Marunda tidak terbukti dipengaruhi secara positif dan signifikan kualitas kehidupan kerja.

\section{Saran}

Berdasarkan uraian hasil dari analisis pengaruh kualitas kehidupan kerja terhadap niatan berhenti kerja dengan kepuasan kerja dan kinerja karyawan sebagai mediasi pada PT. Bina Karya Prima Cabang Marunda, maka terdapat beberapa saran untuk pihak manajemen perusahaan dan juga bagi peneliti selanjutnya, seperti berikut:

- Pertama, karena kepuasan kerja terbukti berpengaruh negatif dan signifikan terhadap niatan karyawan untuk berhenti pada PT. Bina Karya Prima 
cabang Marunda, maka perusahaan perlu memperhatikan faktor-faktor yang mempengaruhi kepuasan kerja karyawan, seperti faktor gaji, promosi, kepuasan terhadap rekan kerja, kepuasan terhadap atasan, hingga kepuasan terhadap pekerjaan itu sendiri. Misalnya dengan memberikan gaji yang memadai sesuai dengan tanggung jawab pekerjaan, memberikan kenaikan jabatan kepada karyawan yang berprestasi, dan juga menciptakan lingkungan kerja yang harmonis antar rekan kerja hingga atasan, sehingga dengan terciptanya kepuasan kerja karyawan dapat mempengaruhi keinginan karyawan itu sendiri untuk tetap bekerja dalam perusahaan.

Kedua, karena kinerja karyawan terbukti berpengaruh negatif dan signifikan terhadap niatan karyawan untuk berhenti pada PT. Bina Karya Prima cabang Marunda, maka disarankan agar perusahaan memerhatikan cara-cara yang dapat dilakukan untuk meningkatkan kinerja karyawan, misalnya memberikan pelatihan yang cukup kepada karyawan. Adanya pelatihan akan meningkatkan pengetahuan dan kemampuan karyawan dalam bekerja. Dengan demikian, karyawan juga dapat melakukan pekerjaan secara profesional dan semangat dalam bekerja juga dapat ditingkatkan. Selain itu, pemberian dukungan/ pujian yang bersifat pribadi pada mereka di tempat kerja, perusahaan juga dapat memberikan penghargaan baik secara finansial mau pun nir-finansial, seperti memberikan bonus kepada karyawan atau mengadakan program penghargaan bagi karyawan yang berkinerja baik untuk periode waktu tertentu, dan lain-lain, sehingga karyawan akan merasa bahwa kinerjanya selama ini diapresiasi oleh perusahaan serta karyawan akan merasa senang bekerja di perusahaan dan dapat mengurangi keinginan karyawan untuk meninggalkan perusahaan.
- Ketiga, karena kualitas kehidupan kerja berpengaruh positif dan signifikan terhadap kinerja karyawan pada PT. Bina Karya Prima cabang Marunda, maka disarankan agar perusahaan perlu mempertahankan serta memberikan kualitas kehidupan kerja yang lebih baik lagi. Menyediakan sumber daya yang memadai serta adanya sistem kontrol yang tepat, meningkatkan teknologi dan pengetahuan teknologi di tempat kerja, memberikan kebebasan untuk menerapkan praktik-praktik kerja inovatif kepada karyawan serta memberikan kemudahan akses terhadap informasi yang dibutuhkan untuk melakukan pekerjaannya, agar karyawan memperoleh pengetahuan yang diinginkan, keterampilan dan keahlian yang dibutuhkan untuk mencapai ekspektasi kinerja yang diperlukan untuk melakukan pekerjaannya saat ini, sehingga diharapkan hal tersebut dapat memotivasi karyawan untuk lebih memaksimalkan kinerjanya.

- Keempat, disarankan untuk penelitian selanjutnya, para peneliti dapat mengambil sampel yang lebih besar, karena pada penelitian ini, sampel yang digunakan hanya berjumlah 103 responden. Dengan menambah jumlah sampel diharapkan penelitian dapat dilakukan lebih mendalam lagi dan juga penelitian nantinya dapat dilakukan dengan subjek penelitian yang berbeda.

\section{DAFTAR PUSTAKA}

Barlow, J. \& Hainsworth, J. (2001). Volunteerism among older people with arthritis. Ageing and Society. 21(2): 203-217.

Bilimoria, D., Perry, S., Liang, X., Stoller, E., Higgins, P., dan Taylor, C. (2006). How do female and male faculty members construct job satisfaction? The roles of perceived institutional leadership and mentoring and their mediating 
processes. The Journal of Technology Transfer, 31(3), 355365. doi: 10.1007/s10961-0067207-z.

Borman, W. C., White, L. A., Pulakos, E. D. dan Oppler, S. H. (1991). Models of supervisory job performance ratings. Journal of Applied Psychology. 76:863-872.

Bos, J. T., Donders, N. C. G. M., Bouwman-Brouwer, K.M., dan Gulden, J. W. J. V. d. (2009). Work characteristics and determinants of job satisfaction in four age groups: university employees' point of view. Int Arch Occup Environ Health. 82:1249-1259. DOI 10.1007/s00420-009-0451-4.

Bycio, P., Hackett, R., dan Alvares, K. (1990). Job performance and turnover: A review and metaanalysis. Applied Psychology: An International Review. 39. 47-76.

Cascio, W. F. (1998). Managing Human Resources: Productivity, Quality of Work Life, Profits. 5th ed. International ed.

Cellucci, A.J. \& DeVries, D.L. (1978). Measuring Managerial Satisfaction: A Manual for the MJSQ Technkal Report II (Center of Creative Leadership).

Chen, S., \& Liu, P. (2012). Effects of internal marketing, organizational commitment, job involvement and job satisfaction on work performance: A study of the elderly care institutions in Taiwan. Marketing Review, 9(3): 277-302.

Crossman, A. \& Abou-Zaki, B. (2003). Job satisfaction and employee performance of Lebanese banking staff. Journal of Managerial Psychology. 18(4): 368-376.

Edwards, B. D., \& Bell, S. T. (2008). Relationships between facets of job satisfaction and task and contextual performance. Applied Psychology: An International Review. 57(3): 441-465.
Egan, T. M., Yang, B. \& Barlett, K. R. (2004). The Effects of Organizational Learning Culture and Job Satisfaction on Motivation to Transfer Learning and Turnover Intention. Human Resource Development Quarterly. 15(3): 279-301.

Fu, W. \& Deshpande, S. P. (2014). The Impact of Caring Climate, Job Satisfaction, and Organizational Commitment on Job Performance of Employees in a China's Insurance Company. Journal of Business Ethic. 124(2): 339-349.

Griffeth, R., Hom, P., \& Gaertner, S. (2000). A meta-analysis of antecedents and correlates of employee turnover: Update, moderator tests, and research implications for the next millennium. Journal of Management. 26: 463-488.

Hariandja, M. T. E. (2002). Manajemen Sumber Daya Manusia. Jakarta: Grasindo.

Harris, G. E, \& Cameron J. E. (2005). Multiple dimensions of organizational identification and commitment as predictors of turnover intentions and psychological well-being. Canadian Journal of Behavioral Science. 37(3), 159-169.

Hasanmoradi. N. (2011). Relationship between The Quality Of Work Life and Job Satisfaction Among The Teachers Of Public and Non-Public Schools in Tehran. International Journal of Arts \& Sciences.

Hira, A., \& Waqas, I. (2012). A Study of job satisfaction and IT's Impact on the performance in the banking industry of Pakistan. International Journal of Business and Social Science. 3(19): 174-180. 
Hofaidhllaoui, M. \& Chhinzer, N. (2014). The Relationship Between Satisfaction and Turnover Intentions for Knowledge Workers. Engineering Management Journal. 26(2):3-9.

Hom, P.W. \& Griffeth, R.W. (1991). A structural equation model of the process of employee turnover: cross-sectional and longitudinal tests. Journal of Applied Psychology. 76(3):350-66.

Iqbal, M. T., Latif, W., \& Naseer, W. (2012). The impact of person job fit on job satisfaction and its subsequent impact on employees performance. Mediterranean Journal of Social Sciences. 3(2): 523-530.

Jamal, M. (1997). Job stress, satisfaction and mental health: An empirical examination of self employed and non-self employed Canadians. Journal of Small Bussiness Management. 35 (4), 48-57.

Jaramillo, F., Mulki, J. P. dan Solomon, P. (2006). The Role of Ethical Climate on Salesperson's Role Stress, Job Attitudes, Turnover Intention, and Job Performance. Journal of Personal Selling and Sales Management. 26(3), 271282.

Jones, E., Kantak, D. M., Futrell, C. M. dan Johnston, M. W. (1996). Leader Behavior, Work-Attitudes, and Turnover of Salespeople: An Integrative Study. Journal of Personal Selling and Sales Management. 16(2), 13-23.

Kim, C.W., McInerney, M.L. \& Alexander, R. P. (1999). Job satisfaction related to safety performance: A case from manufacturing firm. $J$. CoastalBus. 1:63-71.

Kim, T-S. dan Yoo, H-W. (2010). Information Security Professionals' Turnover Intention and Its Causes. Journal of the Korea Institute of Information Security and Cryptology. 20(1): 95-104.
Lai, M-C. \& Chen, Y-C. (2012). SelfEfficacy, Effort, Job Performance, Job Satisfaction, and Turnover Intention: The Effect of Personal Characteristics on Organization Performance, International Journal of Innovation, Management and Technology. 3(4):387-391.

Laschober, T. C. dan Eby, L. T. d. T. (2013). Substance Use Disorder Counselors' Job Performance and Turnover after 1 Year: Linear or Curvilinear Relationship? Adm Policy Ment Health. 40:300-310.

Luscombe, J., Lewis, I. \& Biggs, H. C. (2013). Essential elements for recruitment and retention: Generation Y. Education + Training. 55(3): 272-290.

Majumdar, M. N., Dawn, D. \& Dutta, A. (2012). Impact of Quality of Work Life on Job Performance: A Case Study on Indian Telecom Sector. International Journal of Arts \& Sciences. 5(6): 655-685.

Mamik dan Syarif, U. (2016). Manajemen Sumber Daya Manusia. Sidoarjo: Zifatama Publisher.

Martin, T., Price, J., \& Mueller, C. (1981). Job performance and turnover. Journal of Applied Psychology. 66: 116-119.

Mirvis P.H and Lawler, E.E. (1984). Accounting for the Quality of Work Life. Journal of Occupational Behaviour, 5: 197-212.

McEvoy, G., \& Cascio, W. (1987). Do good or poor performers leave? A meta-analysis of the relationship between performance and turnover. Academy of Management Journal, 30, 744-762.

Muindi, F. \& K'Obonyo, P. (2015). Quality of Work Life, Personality, Job Satisfaction, Competence, And Job Performance: A Critical Review of Literature. European Scientific Journal. 11(26): 223-240.

Moser, K. (1997). Commitment in organizations. Psychologies. 41 (4), 160-170. 
Olusegun, S. O. (2013). Influence of Job Satisfaction on Turnover Intentions of Library Personnel in Selected Univerisities in South West Nigeria, Library Philosophy and Practice (e-journal). 914.

Rivai, V. \& dan Sagala, E. J. (2009). Manajemen Sumber Daya Manusia Untuk Perusahaan Dari Teori ke Praktik Edisi Kedua. Jakarta: PT. Rajagrafindo Persada.

Robbins, S. P. dan Coulter, M. (2010). Manajeme. Edisi Kesepuluh. Jakarta: Erlangga.

Sadri, S. \& Goveas, C. (2013). Sustainable Quality of Work Life And Job Satisfaction: An Indian Satisfaction. Journal of Economic Development, Environment, and People, 2(4):26-37.

Shih, H-A. and Susanto, E (2011). Is innovative behavior really good for the firm?: Innovative work behavior, conflict with coworkers and turnover intention: moderating roles of perceived distributive fairness. International Journal of Conflict Management. 22(2): 111 130, https://doi.org/10.1108/1044 4061111126666

Syptak, J.M., Marsland, D.W., \& Ulmer, D. (1999). Job satisfaction: Putting theory into practice. Family Practice Management. Diambil dari http://www.aafp.org/fpm/991000fm /26.html

Suma, S. \& Lesha, J. (2013). Job Satisfaction and Organizational Commitment: The Case of Shkodra Municipality. European Scientific Journal. 9(17): 41-51.
Trevor, C. O., Gerhart, B., \& Boudreau, J. W. (1997). Voluntary turnover and job performance: Curvilinearity and the moderating influences of salary growth and promotions. Journal of Applied Psychology. 82, 44-61.

Valentine, S., Godkin, L., Fleischman, G. M., dan Kidwell, R. (2011). Corporate Ethical Values, Group Creativity, Job Satisfaction and Turnover Intention: The Impact of Work Context on Work Response. Journal of Business Ethics. 98:353372. DOI 10.1007/s10551-0100554-6

Veerasamy, C., Sambasivan, M. \& Kumar, N. (2013). Individual Skills Based Volunteerism and Life Satisfaction among Healthcare Volunteers in Malaysia: Role of Employer Encouragement, Self-Esteem and Job Performance, A CrossSectional Study. PLoS ONE 8(10): e77698. doi:10.1371/journal.pone.0077698.

VanMeter, R.A., Grisaffe, D. B., Chonko, L.B. \& Roberts, J.A. (2013). Generation Y's Ethical Ideology and Its Potential Workplace Implications. Journal Business Ethics. 117:93-109. DOI 10.1007/s10551-012-1505-1.

Williams, C., \& Livingstone, L. (1994). Another look at the relationship between performance and voluntary turnover. Academy of Management Journal. 37:269-298.

Winter, R., Taylor, T. \& Sarros, J. (2000). Trouble at mill: quality of academic work life issues within a comprehensive Australian university. Studies in Higher Education. 25: 279-294.

Wirawan. (2015). Evaluasi Kinerja Sumber Daya Manusia: Teori Aplikasi dan Penelitian. Jakarta: Salemba Empat. 